\title{
Task IV021701A04701
}

Contract DA 44-177-TC-685

USAAML Technical Report 65-35

\section{A PROLEGOMINON TO THE FORECASTING \\ OF TRANSPORTATION DEVELOPMENT}

FINAL REPORT

Prepared by

W. I. Garrison

D. F. Marble

$$
\text { of }
$$

Northwestern University

Evanston, Illinois

for

U.S. ARMY AVIATION MATERIEI ILABORATORIES

FORT EUSTIS, VIRGINIA 